\title{
The Effectiveness of the Summer Immersion Program for Developing Time Management and Metacognitive Thinking Life Skills among Female Secondary School Students in Saudi Arabia
}

\author{
Amani K.Alghamdi* \\ Imam Abdulrahman Bin Faisal University, Kingdom of Saudi Arabia \\ Received: 20/4/2018 \\ Accepted: $13 / 6 / 2018$
}

Neama Abdulsalam

\begin{abstract}
This research aimed at examining the effectiveness of the Saudi Aramco Research Science Initiative (SARSI) Summer Immersion training program for developing time management and meta cognitive thinking life skills among female gifted secondary school students. The research sample comprised 31 female gifted students enrolled in various Saudi secondary schools. Their ages ranged from 15 to 17 years old with an average age of 16.23. The Abdul Salam scale was used for the measuring time-management performance and metacognitive thinking skills in the pre- and post-assessment of the SARSI program. Statistical analysis revealed significant differences between the students' pre- and post-assessments on: a) time management skills; b) the overall meta cognitive thinking life skills and c) two subcategories of metacognitive skills: planning and self-monitoring. However, no significant differences were identified in the pre- and post-assessment for self-assessment.
\end{abstract}

Keywords: Secondary school, gifted students, time management, meta-cognition, life skills.

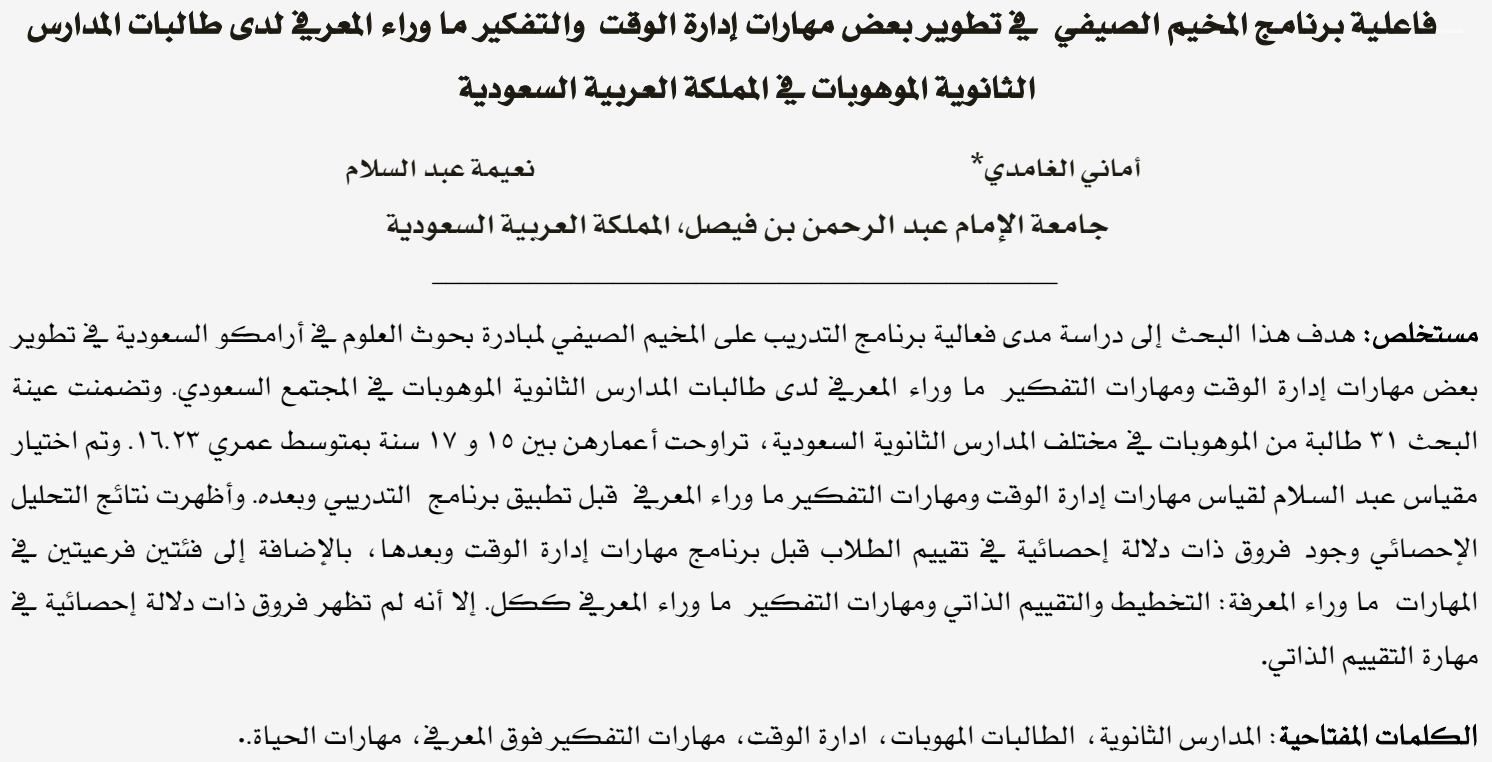

*akhalghamdi@uod.edu.sa 
The Saudi Arabia education system has witnessed an unprecedented improvement in the last decade through implementation of various initiatives, one of which is the focus on student abilities to improve their thinking skills by the Ministry of Education (MoE). A well-known initiative is the King Abdulaziz and His Companions Foundation for Giftedness and Creativity, or Mawhiba, which 'is a national cultural foundation that is by the Custodian of the Two Holy Mosques who supervises it directly and continuously' (The King Abdulaziz and His Companions Foundation for Giftedness and Creativity, 2015, p. 13).

Mawhiba's local summer programs constitute the first stage in which gifted students can identify their potential abilities, offer them appropriate support to nurture and enhance their talent, and prepare them to have effective and distinctive participation in other events, sponsored and presented by Mawhiba, inside and outside the Kingdom.

In line with international standards, like IQ ratio, special talent, qualitative talent, student selection into the Mawhiba program is based on school achievement, teacher recommendation, and achievement test scores. Lohman's (2008) recommended an approach to the identification of students for gifted education be based on four key sources of information: reasoning ability, standardized achievement tests, teacher ratings, and student interest' (Wininger, Adkins, Inman, \& Roberts, 2014, p. 404). The Mawhiba selected students are then invited to join the structured summer immersion program yet it is not mandatory for the students to join the summer program - a rigorous six-week intensive core research program.

Despite some studies on gifted students in Saudi Arabia being available (Alqefari, 2010; Abu Assi, 2012), further research is required to document relevant data in the literature about giftedness education and STEM support in Saudi Arabia. However, this research is amongst the first that aims to examine the effectiveness of the Saudi Aramco Research Science Initiative (SARSI) summer immersion training program for developing some cognitive life skills, such as time-management skills and metacognitive skills among gifted female secondary school students. SARSI, based on the program's literature program, aims to inspire the next generation of Saudi female sec- ondary school students to pursue careers in science, technology, engineering, and mathematics. Therefore, the students were trained to develop their task planning, multitasking, and time management skills.

\section{Research Questions}

The present research aims to answer the following research questions:

1. Are there essential differences in gifted female students' average performance in time-management skills in the pre- and post-assessment that can be attributed to the activities in SARSI?

2. Are there differences in the gifted female students' meta cognitive thinking skills (e.g. self-monitoring, planning, and selfassessment) and the whole degree of meta cognitive thinking skills that can be attributed to the training in the SARSI program?

\section{Literature Review and Theoretical Frame- work}

Few research studies on gifted students in Saudi Arabia have explored the effectiveness of the Mawhiba (Giftedness) program. A recent study by Alghamdi, Hamdan and Abdul Salam Hassan (2016) explored how the Mawhiba (Giftedness) program has helped in developing critical thinking skills for female students in Saudi Arabia. The quantitative study assessed 30 gifted female secondary school students in the Eastern Province of Saudi Arabia, who had participated in the Mawhiba program in the summer of 2015. The results indicate that these students demonstrated improvement in their critical thinking after having attended the intensive scientific program. Another study by Al Qarni (2010, p. 13) based on literature review highlighted that "Only weak and limited studies were conducted to evaluate gifted programs in Saudi Arabia". This raises the importance of conducting more studies about the effect of Mawhiba programs on students' skills and learning, as Al Qarni (2010) further highlighted that no benefits were obtained from these programs, and that the educational authorities have yet to evaluate these programs.

A trend, which is recently replicated by various Saudi Arabia's university summer pro- 
grams, started to emerge in which various partnerships were formed to recruit talented students and immerse them in academic research environment to produce published scientific work. The event is organized annually by Mawhiba in 12 cities, with the participation of 28 leading national firms. According to the organizer, there is a $13 \%$ increase in the number of participating students from last year 2015. Some of the local partners supporting the Mawhiba program are Saudi Aramco, King Abdulaziz City for Science and Technology, King Faisal Specialist Hospital and Research Center, Interactive King Abdullah City for Atomic and Renewable Energy, Prince Sultan University, King Abdulaziz University among others (Tago, 2013). It seems that none of these programs have been researched to validate the advantages for the students in these intensive programs.

Students in these programs are matched with scholars at University of Dammam (UoD) College of Science who are professors in mathematics, biology, physics, and chemistry. Students participate in theory courses, hands-on research, and extracurricular activities to encourage improvement of skills, teamwork, and leadership. The study by Chan (2011) could be most relevant with this paper's context on evaluating the effectiveness of SARSI through the evaluation criteria of its teachers' effectiveness. Chan (2011) further emphasized the importance of considering students' perceptions on not only general but also domainspecific (e.g. science, arts, and music) characteristics and competencies of teachers for gifted learners when evaluating a gifted learning program. Dewey (1913) believed higher levels of interest lead to higher levels of engagement or absorption, as shown in studies that demonstrated higher interest levels resulting in increased involvement (Schiefele, 1991; Tobias, 1994). Furthermore, Mazer (2013a; 2013b) highlighted the correlation between individual interest and engagement. Specifically, emotional interest exhibited a stronger association compared with cognition (i.e. knowledge or competence) (Wininger et al., 2014, pp. 405406).

Life skill is defined in this study as a set of skills that prepare the individual for life and qualifies him/her to deal with and corresponds to various problems with consciousness. It is measured in the current study pre- pared for that scale, and it includes time management skills and metacognitive skills. Time management skills is defined by Hassan as "The ability to positively effective use of time for the completion of various tasks and invest this time, both in academic tasks and invest leisure time and calculates the degree obtained by the student in the scale management skills time and include skills (setting goals - planning - organization - evaluation and take advantage of free time." Meta cognitive thinking skills defined by Hassan as "An individual's ability to describe his / her thinking carefully and monitor his / her performance during the implementation of the various tasks, as well as its ability to develop specific plans to accomplish the tasks entrusted to him/her and the ability to audit itself and evaluated constant$1 y, "$ is measured in the present study through three basic skills (self-monitoring - planning self-evaluation)

\section{The SARSI Program}

In 2005, the first group of Saudi secondary school students attended the RSI at MIT, and a delegation of the kingdom's most promising students has been attended this flagship program every year since 2010. From 2011 to 2013, CEE, in partnership with Mawhiba and Saudi Aramco, led the Saudi Aramco Research Science Initiative (SARSI) at King Abdullah University of Science and Technology (KAUST), which is now managed by KAUST. Their alumni are distinguished, winning accolades at Ibdaa (the Saudi Olympiad for Scientific Creativity) and ISEF in the United States. In the summer of 2015, the Centre of Excellence in Education (CEE) marked the 32nd anniversary of its flagship Research Science Institute (RSI) at MIT, and the 11th year of partnership with Mawhiba to provide the 'RSI experience' to the brightest students in the Kingdom of Saudi Arabia (Sillman, 2015). The 2015 cohort comprised 39 accomplished female secondary school students at the UoD, College of Science for the SARSI program. Some of the subjects focused in this program include the Markov decision process, alpha-globin gene mutations, superconducting materials, and medicinal plants among others. The students were also involved in extracurricular and social activities.

The SARSI scholars first participated in a week of intensive science, technology, engineering, and mathematics (STEM) classes under the 
guidance of distinguished professors. The centerpiece of the RSI is the six-week research internship in which students work on individual projects under the tutelage of mentors who are experienced scientists and researchers. During the final week, students prepare and submit written and oral presentations on their respective research projects. The students began their summer with one week of seminars highlighting current research topics in biology, chemistry, engineering, mathematics, physics, and the humanities. The SARSI evening lecture series began during the first week and continued throughout the summer. It enabled students to meet face-to-face with science and technology leaders, including Nobel laureates and technology entrepreneurs. The students received their preliminary assignments from their research mentors and began to read advanced texts and recent journal articles in the first weekend. Through theoretical classes, hands-on sessions in science laboratories, engagement in cultural activities, and lectures by national and international female leaders, students are trained to develop their skills in metacognitive thinking, which include selfmonitoring, planning and self-evaluation and time management skills, which involve the positive use of time to fulfil multiple tasks including academic tasks.

\section{Method}

\section{Methodology}

The current research follows the quasiexperimental approach, and is based on the design of one - experimental group (pre- and post) design. The current research seeks to determine and understand the effectiveness of the SARSI summer training program for gifted students (the independent variable) in terms of developing various cognitive life skills, including time-management skills and metacognitive skills (the dependent variables). This research has been carried out within an ethical framework and students and their families were invited to fill out an application form before engaging in the research.

\section{Participants}

The population of the study consists of all gifted female students of high secondary school students in Saudi Arabia Eastern Province that nominated (100) female students. Participants in this research sample, were se- lected according to the following criteria: (a) level of academic achievement (95\% or more); (b) nomination by teachers and educational departments; and (c) student aptitude test (SAT) by the National Centre for Measurement and Evaluation, comprised the following groups:

1) A pilot sample was used to calculate the reliability and validity of instruments. It consisted of 32 gifted secondary school students from the Eastern Province of Saudi Arabia. Their ages ranged between 15 and 17 years, with an average chronological age of 16.21 years and a standard deviation of 0.75 .

2) The main sample of the study involved 31 gifted female secondary school students from the Eastern Province of Saudi Arabia. Their ages ranged between 15 and 17 years with an average chronological age of 16.23 years and a standard deviation of 0.74 .

\section{Instruments}

Self-assessment of time management skills. The questionnaire consisted of 40 statements designed to assess students' time management skills, specifically in their ability to organize and plan; implement, evaluate and follow up; and manage their free time. The selfassessment has three levels in which each student marked a tick to represent her actual performance with respect to each behavioral item.

1. This is a self-assessment/self-rated test

2. The assessment is in the form of a questionnaire.

3. The questionnaire uses 3 point simple rank scale ( 3-applicable - 2- sometimes 1-not applicable)

The scale was verified by five professors who specialized in the fields of education and psychology on measurement, instrument design, and sample suitability. Some revisions were made to contextualize the scale. Vocabulary items required four of the five reviewers to approve prior to adoption in the final version. The validity of the instrument revealed a positive correlation between the scale for timemanagement skills (life skill in the present study) and the test for cognitive thinking. The value of the correlation coefficient was .57, which is a statistically significant $(\mathrm{p}<0.001)$. The value of the reliability alpha coefficient was 0.955 for the sample $(n=32)$ of gifted female secondary school students. 


\section{Self-assessment of meta cognitive thinking skills.}

The self-assessment was designed to measure the three basic skills of metacognitive thinking (self- monitoring, planning, and selfassessment) by considering Schraw and Dennison (1994) scale and their list of metacognitive awareness inventory (MAI). A number of tools that addressed the relative variable of metacognitive thinking skills in the Arab and foreign regions were reviewed. The list of knowledge awareness was adapted from Jacobs and Paris' (1987) measurement and the metacognition questionnaire by $\mathrm{O}^{\prime} \mathrm{Neil}$ and Abedie (1996). After the analysis of the tools above and revisions of the three basic skills and their working definitions as components of metacognitive thinking (i.e. self-monitoring, planning, and self-assessment), the instrument comprised 50 statements to measure the three skills and the statements were interchanged from positive statements to negative statements to avoid item familiarity, which could affect the stability of the scale.

To assess validity of the instrument, the researchers used two kinds of validity: face validity and structural validity using Varimax rotation. After rotation, the items of the scale decreased to 36 items only saturated on the three component factors (self-monitoring, planning, self- assessment).

The reliability was calculated using Cronbach's alpha. The value of reliability coefficients of the three dimensions: selfmonitoring, planning, and self-assessment were .78, .76. and .65, respectively. Alpha for the metacognitive thinking was .89. Alphas for the current research were $.93, .87, .85$, for the three scales, self-monitoring, planning, and self-assessment, respectively.
Research Question 1: Are there essential differences in gifted female students' average performance in time-management skills in the pre- and post-assessment that can be attributed to the activities in SARSI? To answer this question the researchers use t-test for paired samples. Table 1 shows the results.

There were essential significant differences between the mean scores of the pre- and postassessment on time management skills in favors of telemetric as the value of $t$ (2.237), and this value was significant at $(.03) \mathrm{P}$ - value $=$ .03 (see Table 1).

The impact of the program on the development of time-management skills was considerable $(v 2=0.143)$, which strongly indicated the effectiveness of the training program in terms of developing time-management skills among gifted students.

Research Question 2: Are there essential differences in the gifted female students' meta cognitive thinking skills (e.g. self-monitoring, planning, and self-assessment) and the whole degree of meta cognitive thinking skills that can be attributed to the training in the SARSI program? To answer this question the researchers used t-test for paired sample.

The essential significant differences between the mean scores for the gifted students' skills in self-monitoring, planning, and metacognitive thinking are illustrated in Table 1 . The $\mathrm{t}-$ value for self-monitoring skills in the pre- and post-assessment is (2.58), with a statistically significant value at (0.01), but for planning skills, the t-value is (2.84) with the level of significance at (.001). For metacognitive thinking skills, the t-value is (3.230) with a level of significance at (.001). The impact of all three

Table 1

Mean, Standard Deviation, T-Test (Pre - Post) in Time Management Skills ( $\mathbf{n}=31$ )

\begin{tabular}{lcccccccl}
\hline \multirow{2}{*}{ variable } & \multicolumn{7}{c}{ Pre } & \multicolumn{7}{c}{ Post } & & & \\
\cline { 2 - 9 } & M & SD & M & SD & t-value & d.f. & Eta squared & Effect size \\
\hline Time - Management skills & 86.09 & 17.76 & 90.70 & 19.31 & $2.24^{* *}$ & 30 & 0.143 & Large \\
\hline
\end{tabular}

Table 2

Mean, Standard Deviation and T-Test for (Pre - Post) in Metacognitive Thinking Skills ( $\mathbf{n}=31$ )

\begin{tabular}{|c|c|c|c|c|c|c|c|c|}
\hline & \multicolumn{2}{|c|}{ Pre } & \multicolumn{2}{|c|}{ Post } & \multirow[t]{2}{*}{$\mathrm{t}$} & \multirow[t]{2}{*}{ df } & \multirow[t]{2}{*}{ eta } & \multirow[t]{2}{*}{ Effect size } \\
\hline variable & $\mathrm{M}$ & SD & $\mathrm{M}$ & SD & & & & \\
\hline Self-monitoring & 41.58 & 8.89 & 43.93 & 9.85 & $2.58^{* *}$ & 30 & 0.181 & Large \\
\hline Planning & 20.83 & 3.02 & 22.16 & 2.65 & $2.84^{* *}$ & 30 & 0.210 & Large \\
\hline Self-assessment & 23.25 & 2.52 & 22.93 & 4.72 & 0.634 & 30 & 0.086 & n.s. \\
\hline Total & 83.48 & 13.04 & 91.32 & 8.82 & $3.230^{* *}$ & 30 & 0.258 & Large \\
\hline
\end{tabular}


variables is high with scores of $(0.181,0.210$, $0.258)$, respectively. However, there are no statistically significant differences between the gifted students' mean scores for selfassessment skills in the pre- and postassessment as the value of $\mathrm{t}$ value is $0.634(p>$ $.05)$.

\section{Discussion}

On the effectiveness of SARSI in relation to other programs, students gave feedback that was equal on both scales. Parents and students were excited yet somewhat concerned. The concern was related to the prospect of sending young girls out on their own to present themselves, especially students from other cities in Saudi Arabia, such as Jeddah and Riyadh.

The results of this research point towards the importance of tight and precise planning as well as of educational and professional experience. The training process for the students, ranging from the activities held on the first day of the camp to the organizational planning of all tasks and activities in all scientific and literary fields, contributed to the selfmanagement skills of the participating students. Professional feedback from supervisors and teachers had a great impact in helping students plan, develop, and implement specific goals and strategies under the guidance and supervision of the trainers.

This result can be attributed to the students' commitment to attend the full program of training sessions and to complete their activities at specified times according to the plan. This commitment created and reinforced their regulation and self-control abilities. Hassan's (2004) findings support the conclusion that there exists a correlation between metacognitive thinking skills and personality traits (namely self-confidence, responsibility, perseverance, and flexibility). These attributes were probably strengthened as a result of the act of participating in the activities and as a result of the specific contents of the program related to the development of metacognitive thinking skills. The study by Swan et al., (2015, p. 309) clarified that "A large majority of students perceived their experience in the lab was helping them develop skills", which include "Interpersonal and collaborative skills, communication, creativity, critical thinking and problem solving, curiosity, organization, and per- sistence and motivation". Their study revealed that, "Experience provided opportunities that furthered the development of student critical thinking, problem solving skills, and students felt that the accelerated course work helped them to develop these skills', and 'Enhanced how creative they are with ways of thinking...[through] Alternate assignments and assignment options' (Swan et al., 2015, p. 310). This form of learning, accelerated and diverse, is similar to the SARSI program.

Results in this study confirms Rogers (2007) in that this type of blended learning provides daily challenge in the gifted students' specific area of talent, regular opportunities to be unique, independent work in their areas of passion and talent, various forms of subjectand grade-based acceleration as their educational needs require, opportunities to socialise and learn with like-ability peers, and differentiated instruction in pace, amount of review and practice, and organisation of content presentation. "Providing gifted learners with appropriate choices for accelerated coursework in their area of talent or interest in this type of blended-learning (in which there is an emphasis and amalgamation or practical and theoretical aspects) model can help them meet their potential for academic achievement, while remaining within their brick-and-mortar environment". (Swan et al., 2015, p. 315).

In addition, earlier intervention is required in order to stimulate students' interest, at an early age, in science. Researchers, such as Keeley (2009), Lindahl (2007), Maltese and Tai, (2010), and Robinson et al., (2014, p. 190), have recommended early intervention in science to maximise the cumulative learning processes that are critical to science talent development. In support of early opportunities, researchers argued that science interest is usually ignited before middle school and is instrumental in motivating students to develop their talents and to pursue science as a career option. This is in coordination with the SARSI program and this should make the result supportive of future similar initiatives.

Future research could focus on teacher training. How well do teachers in such programs measure up to Chan's (2011) criteria of highly effective teachers in gifted programs in general? The required competencies of teachers in gifted education might differ based on the 
specific content domains and target gifted subpopulations (see Feldhusen, 1997); however, Chan (2011, cited Dubner, 1980) explained that ideal teacher competencies should include effective approaches to different subgroups of gifted and talented children, sensitivity to individual student needs, and the capabilities to meet these needs.

Future research in the area of how SARSI focus on higher order thinking skills would be of significance.

\section{Implications for Practice and Conclusion}

The SA-RSI program offers training and support opportunities to students with high abilities, with specific focus on STEM. According to Hidi and Renninger (2006), "Students with high levels of well-developed individual interest are purported to regularly engage with the content and not to give up when faced with challenges" (cited in Wininger et al., 2014, p. 407). This is true for Mawhiba students. Mawhiba, as the official national sponsor for gifted students, and the partner-universities across Saudi Arabia offer summer programs for gifted students; therefore, this initiative is considered part of the early intervention strategies to support gifted students' learning, especially in STEM. Such programs support the literature that states, "Talent development in science should begin prior to university with investigative opportunities to encourage curiosity and engagement so that interest in science will be maintained as students' progress across grade levels" (Brandwein, 1995; Maltese \& Tai, 2010; Marshall, McGee, McLaren, \& Veal, 2011; Metz, 2008; National Association for Gifted Children, Task Force on Math and Science, 2008; Roberts, 2010).

\section{Acknowledgement}

This research would not be possible without the administrative support of The University of Dammam, College of Science, Saudi Aramco, Center of Excellence in Education (CEE)/Scientific Research Institute (SRI for MIT), and King AbdulAziz and his Companion Foundation for Giftedness and Creativity.

\section{References}

Abu Assi, D. (2012). Time management among academically gifted and their relationship to the level of ambition. Journal of the College of Education. El-Arish, Suez Canal Universi- ty.

sro4.eulc.edu.eg/eulc_v5/Libraries/Thesis/Brow seThesisPages.aspx?fn...BibID.

Alghamdi, H., \& Abdul Salam, H., N. (2016). The effectiveness of the mawhiba program for the development of critical thinking skills among gifted female students at the secondary levels. British Journal of Education, Society \& Behavioral Science, 14( 2) 1-13.

Al Qarni, M. A. (2010). Evaluation of provision for gifted students in Saudi Arabia (Unpublished Doctoral Dissertation). University of Wollongong, Wollongong.

Alqefari, A. (2010). A study of program memes for gifted students in the Kingdom of Saudi Arabia. (Unpublished Doctoral Dissertation). Brunel University, London.

Brandwein, P. F. (1995). Science talent in the young expressed within ecologies of achievement (RBDM 9510). Storrs, CT: The National Research Centre on the Gifted and Talented, University of Connecticut.

Chan, D. W. (2011). Characteristics and competencies of teachers of gifted learners: The Hong Kong student perspective. Roeper Review, 33,160-169.

Dewey, J. (1913) Interest and effort in education. Boston, MA: Riverside.

Dubner, F. (1980). Thirteen ways of looking at a gifted teacher'. Journal for the Education of the Gifted, 3, 143-146.

Feldhusen, J. F. (1997). Educating teachers for work with talented youth. In N. Colangelo \& G. A. Davis (Eds.), Handbook of gifted education (2nd edition) (pp. 547-552). Boston, MA: Allyn \& Bacon.

Feldhusen, J. F., \& Hoover, S. M. (1986). A conception of giftedness: Intelligence, selfconcept and motivation. Roeper Review, 8(3), 140-143.

Getzels, J. W., \& Jackson, P. W. (1962). Creativity and intelligence. New York: Wiley.

Guilford, J. P., \& Christensen, P. R. (1973). The one-way relation between creative potential and IQ. Journal of Creative Behavior, 7, 247252.

Hassan, A. N. (2004). Metacognition and its relationship with some personality traits among 
undergraduate students, (Unpublished Master's Thesis). Suez Canal University, Suez .

Hassan, A. N. (2015). Time management skills and its relation to quality of life among girls, Dammam University Education College students and its effects on their achievement. Journal of Education, Al Azhar University, 163, 53-94.

Jacobs, J. E., \& Paris, S. G. (1987). Children's metacognition about reading: Issues in definition, measurement, and instruction', Educational Psychologist, 22, 255-278.

Keeley, P. (2009, April 22). 'Elementary science education in the K-12 system' NSTA WebNews Digest. From:

http:/ / www.nsta.org/publications/news/ story.aspx?id=55954].

Lindahl, B. (2007). A longitudinal study of students'attitudes towards science and choice of career. Paper presented at the 9th NARST International Conference, New Orleans, Louisiana.

Lohman, D. F. (2008). Identifying academically talented students: Some general principles, two specific procedures. in L. V. Shavinina (ed). International handbook on giftedness (pp. 971-997). Dordrecht, The Netherlands: Springer.

Maltese, A. V., \& Tai, R. H. (2010). Eyeballs in the fridge: Sources of early interest in science. International Journal of Science Education, 32, 669-685. doi:10.1080/09500690902792385

Marshall, S. P., McGee, G. W., McLaren, E., \& Veal, C. C. (2011). Discovering and developing diverse STEM talent: Enabling academically talented urban youth to flourish', Gifted Child Today, 34(10), 16-23.

Mazer, J. (2013a) 'Associations among teacher communication behaviours, student interest, and engagement: A validity test'. Communication Education, 62, 86-96. doi:10.1080/03634523.2012.731513

Mazer, J. (2013b) 'Student emotional and cognitive interest as mediators of teacher communication behaviours and student engagement: An examination of direct and interaction effects'. Communication Education, 62, 253-277. doi:10.1080/03634523.2013.777752

Metz, K. E. (2008) 'Narrowing the gulf between the practices of science and the elementary school science classroom', The Elementary School Journal, 109, 138-161.

National Association for Gifted Children, Task Force on Math and Science. (2008) The STEM promise: Recognizing and developing talent and expanding opportunities for promising students of science, technology, engineering and mathematics. From:

http:/ /www.nagc.org/uploadedFiles/STE M\%20white\%20paper\%281\%29.pdf].

O’Neil, H. F. \& Abedi, J. (1996). Japanese children's trait and state worry and emotionality in a high-stakes testing environment. Anxiety, Stress, and Coping, 5, 253-267.

Roberts, J. L. (2010). Talent development in STEM disciplines: Diversity - Cast a wide net. National Consortium for Specialized Secondary Schools of Mathematics, Science, and Technology, 16(1), 7-9. From: http:/ / www.ncsssmst.org/publications/jo urnal/63spring-2010-journal].

Robinson, A., Dailey, D., Hughes, G., \& Cotabish, A. (2014). The effects of a sciencefocused STEM intervention on gifted elementary students' science knowledge and skills', Journal of Advanced Academics, 25(3), 189-213.

Rogers, K. B. (2007). Lessons learned about educating the gifted and talented: A synthesis of the research on educational practice. Gifted Child Quarterly, 51(4), 382-396.

Schiefele, U. (1991). Interest, learning, and motivation. Educational Psychologist, 26, 299323.

Swan, B., Coulombe-Quach, X.-L., Huang, A., Godek, J., Becker, D., \& Zhou, Y. (2015). Meeting the needs of gifted and talented students: Case study of a virtual learning lab in a rural middle school. Journal of $A d-$ vanced Academics, 26(4), 294-319.

Tago, A. (2013). 2750 students to participate in mawhiba summer program SAUDI ARABIA.From:

athttp://www.arabnews.com/news/45468 0\#. 
The King Abdulaziz and His Companions Foundation for Giftedness and Creativity .(2015). from http://www.mawhiba.org.sa/AR/Pages/ home.aspx

Tobias, S. (1994). Interest, prior knowledge, and learning. Review of Educational Research, 64, 37-54. doi:10.2307/1170745

Torrance, E. P. (1980). Creative intelligence and "an agenda for the 80 's. Art Education, $33,8-14$.

Van Tassel-Baska, J. (1989). Profiles of precocity: A three-year study of talented adolescents. In J. Van Tassel-Baska \& P. Olszewski -Kubilius (eds) Patterns of influence on gifted learners: The home, the self, and the school (pp. 29-39). New York: Springer Netherlands.

Wininger, S. R., Adkins, O., Inman, T. F., \& Roberts, J. (2014). Development of a student interest in mathematics scale for gifted and talented programming identification. Journal of Advanced Academics, 25(4), p. 403-421. 